DOI: $10.17805 /$ zpu.2015.3.34

\title{
О применении математических методов в культурологии в свете тезаурусного подхода
}

\author{
И. А. ГРИГОРЬЕВА \\ (МОСКОВСКИЙ ГУМАНИТАРНЫЙ УНИВЕРСИТЕТ)
}

В статье приведен пример адаптации методов математической статистики - корреляционного и факторного анализов с целью изучения объектов культуры, в частности художественного текста.

Метод анализа концепта, который соотносится с моделью тезаурусного подхода Вал. А. Лукова и Вл. А. Лукова, был предложен В. А. Масловой. Он состоит из следующих уровней: анализ этимологического, лексического, паремиологического и контекстуального значений выбранного концепта.

Анализ лексемы "trommel" (нем. барабан) на означенных уровнях - этимологическом, лексическом, паремиологическом и контекстуальном уровнях (художественные тексты Г. Белля, Л. Фейхтвангера, Б. Брехта, Т. Манна и Г. Грасса) показал, что выявленная новая структура значительно расширяет смысловую нагрузку понятия лексемы, дополняя ее новыми концептуальными значениями. Смысловой концептуальный объем лексемы "trommel" позволяет определять ее как универсальный, смыслообразующий и смыслоформирующий концепт в тезаурусе германской картины мира.

Использование математических методов (корреляционный и факторный анализы) позволяет выявить коэффициент корреляции значений, а также определить структурные компоненты концепта. Указанные методы дают возможность получить объективные данные при исследовании концептов, а также и других объектов культуры (живописи, архитектуры, музыки, литературы и т. д.).

Ключевые слова: тезаурусный подход, концепт, структура концепта, коэффициент корреляции.

$\mathrm{O}$ собенности жизненного пути и образа жизни индивидуальны для каждого человека, как и уникальность тезауруса, который является воплощением не только творческого осмысления мира самим человеком, но и результатом влияния ряда факторов, типизирующих его поведение.

В контексте тезаурусного подхода мы понимаем тезаурус как систематизированную совокупность знаний субъекта, которая связана с его положением в социальнокультурных отношениях в обществе.

По предположению Вал. А. Аукова и Вл. А. Аукова, первооснова тезауруса - концепт, соединяющий в себе выраженный в нем смысл, эмоционально-чувственное восприятие внутреннего образа (Ауков Вал., Ауков Вл., 2008: 111; 2013: 74-78).

Метод анализа концепта, который соотносится с моделью тезаурусного подхода Вал. А. Аукова и Вл. А. Аукова, был предложен В. А. Масловой (Маслова, 2011: 58). Он состоит из следующих уровней: анализ этимологического, лексического, паремиологического и контекстуального значений выбранного концепта.

Анализ лексемы trommel (нем. барабан) на означенных уровнях - этимологическом, лексическом, паремиологическом и контекстуальном уровнях (художественные тексты Г. Белля, $\Lambda$. Фейхтвангера, Б. Брехта, Т. Манна и Г. Грасса) показал, что выявленная новая структура значительно расширяет смысловую нагрузку понятия лексемы, дополняя ее новыми концептуальными значениями: время и пространство (как единый фактор) - ритм/порядок - память - alter ego - учитель и др. (Григорьева, Ясинская, 2013, 2014). 
Целью данной статьи является попытка доказать универсальность концепта trom$m e l$ и проанализировать способность к адаптации математических методов в исследовании объектов культуры.

Полученные значения образуют концептуальное пространство лексемы trommel. (В данном случае существенно, что термины «значение» и «смысл» имеют разное содержание. Значения слов представлены в словарях и имеют общепринятый характер, в то время как смыслы отражают личностное понимание людьми того или иного феномена, в том числе обусловленного культурой данного народа. Тем самым образуется новая система концептуальных значений.)

Аля выявления существующих взаимосвязей между отдельными значениями концепта был использован метод ранговой корреляции rs Спирмена, представленный в компьютерной программе «Статистика». Установленные в данном исследовании корреляционные связи являются максимально значимыми и тесными (максимальное возможное абсолютное значение коэффициента корреляции $r=1,00$; минимальное $\mathrm{r}=0$ ) (Сидоренко, 2010: 203). Так как между всеми значениями присутствует сильная корреляционная связь $(\mathrm{r} \geq 0,70)$, в статье мы рассмотрим взаимосвязи с максимальным коэффициентом корреляции $r=1,00$. Выявляемые корреляционные связи могут быть двух типов: положительные и отрицательные. Положительные связи между показателями свидетельствуют о том, что при увеличении одного показателя увеличивается другой. При отрицательных корреляционных связях проявляется обратно пропорциональная зависимость: при увеличении одного показателя уменьшается другой.

Понятия «жестяная кружка», «жестяная труба, отводящая водус крыш», «кухонная вытяжка», "жестяной чилиндр для варки кофе», "сито и звук, им издаваемьй», «сачок для ловли куропаток» положительно связаны между собой, создавая, таким образом, единую группу понятий. Аанная совокупность значений позволяет нам назвать эту группу - «предметы быта».

Понятия «бесполезное действие», «пустые слова», «пустое помещение» также связаны между собой положительно и составляют, по нашему мнению, группу значений, которую можно обозначить, как «бесполезность, пустота».

Понятия «ценность», «спутник» связаны между собой положительно и позволяют объединить их в группу - «значимый объект».

Понятия «объект любви», «спаситель» также положительно связаны между собой. Эту группу понятий можно назвать - «объект надежды».

Таким образом, концептуальное пространство лексемы trommel охватывает основные сферы функционирования личности и общества: бытовую, чувственную, трудовую, интеллектуальную и т. А.

С целью дальнейшего анализа значений лексемы trommel был проведен факторный анализ, который позволил выявить структуру изучаемого концепта (Факторный ..., 1989). Факторный анализ нацелен на решение следующих задач: описать объект измерения всесторонне и в то же время компактно, объединив отдельные значения в составе одной общей группы. Таким образом, фактор объединяет в своем составе некоторые значения, наиболее тесно связанные между собой и образующие тем самым единое целое.

Использование факторного анализа позволило выявить семь факторов в структуре концепта trommel.

В состав первого фактора, который мы можем назвать «демиург», входит 30 значений. Все эти значения можно по смыслу объединить в отдельные группы: круг бараба- 
на - это круг бытия (мира, вселенной); кожа, которая натянута на нем, - это абсолютное существование, а удар в него ? это вступление божественного воодушевления, которое переносится на абсолютное бытие. "Ритм», "порядок», «время», "nространство» - базовые категории жизни, установленной на земле Творцом. «Память» заключает в себе прошлое, настоящее, будущее. "Защита», "nокров», "опора»как выражение покровительства и помощи. "Коммуникатор», «друг», «слуга», "спутник», «личность» - одушевленные понятия. По сути, здесь имеет место наделение барабана человеческими качествами, дарующими полноценное общение и поддержку. "Средство успокоения», «пища» (как духовная категория) - факторы гармонизации, соединения с Творцом.

В состав второго фактора - «пространство быта» - входят следующие значения: "жестяная труба, отводящая воду с крыш», "кухонная вытяжка», "пустое помещение», предметы, организующие пространство жилища. "Жестяной илилиндр для варки кофе», "жестяная кружка», "сито и звук, им издаваемьий - приспособления Аля употребления пищи; “сачок для ловли куропаток» - средство для добывания пищи. Все эти предметы организуют бытовое пространство человека, а также служат удовлетворению потребности в питании.

Третий фактор - «бесполезность». «Пустой человек», "бесполезное действие», «nустые слова»- это отсутствие переживаний, идей, мыслей, неспособность синтезировать новую информацию. "Пустой человек» - это человек, за словами которого не следует никакого действия. Отсутствие содержания - это отсутствие индивидуальности, смыслового наполнения.

Четвертый фактор - «противоречивость чувств». Амбивалентные значения «объект любви» - «ненависть» показывают напряженность чувств. Значение «кожа, натянутая на барабан» в данном контексте - отдать «под барабан», т. е. в солдаты. Исторически барабан использовался в шаманских ритуалах; считалось, что барабан поет голосом животного, принимавшим участие в его создании. В шаманской игре на барабане ничто не может заменить вибрацию энергии, исходящей от кожи, которая была снята с животного. В Германии же данное выражение является пренебрежительным, означает, что человека отдали в солдаты.

Пятый фактор - «демонстрация расового превосходства». «Истинный германеи». Согласно теориям, появившимся на рубеже XIX-XX вв., именно в Северной Европе сохранился наиболее «чистый арийский расовый тип», тогда как жители других стран являются плодом смешения «арийцев» с аборигенами. Из этого следовал вывод о расовом превосходстве жителей Северной Европы, которые являются наиболее «чистыми и совершенными» носителями «арийского духа» (которому приписывались все достижения европейской культуры). Жозеф Артур де Гобино написал: «Вся человеческая культура, все достижения искусства, науки и техники, свидетелями которых мы сегодня являемся, - плоды творчества арийцев... Он [ариец] - Прометей человечества, со светлого чела которого во все времена слетали искры гениальности, разжигающие огонь знаний, освещающий мглу мрачного невежества, что позволило человеку возвыситься над другими существами Земли» (цит. по: Воропаев, 1996: 187).

Шестой фактор - «посредник». Значение «просеиватель для жидкости, зерна», как фильтр для отделения всего ненужного, несущественного. «Барабан, как архитектурный элемент» - основание для купола (соединяет «тело храма» с его «главой»), посредничество для создания важного целого с одновременным отделением всего несущественного и второстепенного; объединение и фильтрация. 
Седьмой фактор - «защита». Значение «перепонка, закрыъающая слуховой канал» - как защита слуха, защита основного канала, через который приходит информация из окружающего мира, таким образом, как защита важных ценностей.

Таким образом выявленный смысловой концептуальный объем лексемы trommel, позволяет определять ее как универсальный, смыслообразующий и смыслоформирующий концепт, который не только образует новые концептуальные значения в тезаурусе германской картины мира, но и генерирует новые смыслы. Использование математических методов (корреляционный и факторный анализы) позволяет выявить коэффициент корреляции значений, а также определить структурные компоненты концепта. Указанные методы дают возможность получить объективные данные при исследовании концептов, а также и других объектов культуры (живописи, архитектуры, музыки, литературы и т. А.).

\section{СПИСОК АИТЕРАТУРЫ}

Воропаев, С. (1996) Энциклопедия Третьего Рейха. М. : Аокид-Миф. 589 с.

Григорьева, И. А., Ясинская, М. Б. (2013) Концепт trommel ('барабан') в тезаурусе романа Г. Грасса «Жестяной барабан» // Тезаурусный анализ мировой культуры : сб. науч. трудов. Вып. 27. Специальный выпуск. Высшее образование для XXI века: X Международная научная конференция. Москва, 14-16 ноября 2013 г. Аоклады и материалы. Симпозиум «Тезаурусный анализ мировой культуры» / под общ. реА. Вл. А. Аукова. М. : ИзА-во Моск. гуманит. ун-та. 80 с. C. 66-73.

Григорьева, И. А., Ясинская, М. Б. (2014) Топика романа Гюнтера Грааса «Жестяной барабан» // Научные труды Московского гуманитарного университета. № 10. С. 23-30.

$\Lambda$ уков, В. А., уков, Вл. А. (2008) Тезаурусы: Субъектная организация гуманитарного знания. М. : Нац. ин-та бизнеса. 784 с.

Иуков, В. А., Ауков, Вл. А. (2013) Тезаурусы II: Тезаурусный подход к пониманию человека и его мира. М. : Нац. ин-та бизнеса. 640 c.

Маслова, В. А. (2011) Введение в когнитивную лингвистику. 5-е изд. М. : Флинта ; Наука. $296 \mathrm{c}$.

Сидоренко, Е. В. (2010) Методы математической обработки в психологии. СПб. : Речь. 350 с.

Факторный, дискриминантный и кластерный анализ (1989) / Аж.-О. Ким, Ч. У. Мьюллер, У. Р. Клекка и др.; пер. с англ. ; под ред. И. С. Енюкова. М. : Финансы и статистика. 215 с.

Аата поступления: 13.05 .2015 г.

\section{USING MATHEMATICAL METHODS IN CULTUROLOGY IN THE LIGHT OF THE THESAURUS APPROACH \\ I. A. GRIGORIEVA \\ (MOSCOW UNIVERSITY FOR THE HUMANITIES)}

The article provides an example of adapting such methods of mathematical statistics as correlation and factor analysis to studying objects of culture, in particular a literary text.

Our method of concept analysis, which is in accordance with the thesaurus model suggested by Val.A. Lukov and Vl.A. Lukov, was suggested by V.A. Maslova. It comprises the following levels of analysis, concentrating correspondingly on etymological, lexical, paremiological and contextual meanings of the concept selected.

Our analysis of the 'trommel' concept (German for 'drum') on all of the four levels in the texts by H. Böll, L. Feuchtwanger, B. Brecht, Th. Mann and G. Grass has shown that the newly identified structure greatly increases the semantic load of the lexeme, adding a number of conceptual meanings to it. The volume of conceptual meaning found in the 'trommel' shows it to be a universal concept which both creates new concepts in the thesaurus of German world view and generates new meanings. 
The use of mathematical methods (correlation and factor analysis) helps us discover the meaning correlation quotient, as well as identify the structural components of a concept. These methods offer an opportunity to obtain objective data on concepts and other objects of culture, including those of painting, architecture, music; literature, etc.

Keywords: thesaurus approach, concept, concept structure, correlation quotient.

\section{REFERENCES}

Voropaev, S. (1996) Entsiklopediia Tret' ego Reikba [The Encyclopedia of the 3rd Reich]. Moscow, Lokid-Mif Publ. 589 p. (In Russ.).

Grigorieva, I. A. and Yasinskaya, M. B. (2013) Kontsept trommel ('baraban') v tezauruse romana G. Grassa «Zhestianoi baraban» [The concept of trommel ('drum') in the thesaurus of Günter Grass' novel "The Tin Drum"]. In: Tezaurusnyi analiz mirovoi kul'tury [Thesaurus analysis of world culture] : A collection of articles. Issue 27: Spetsial' nyi vypusk. Vysshee obrazovanie dlia XXI veka: $X$ Mezbdunarodnaia nauchnaia konferentsiia. Moskva, 14-16 noiabria $2013 \mathrm{~g}$. Doklady $i$ materialy. Simpozium "Tezaurusnyi analiz mirovoi kul'tury" [Special issue. Higher education for the $21^{\text {st }}$ century. The $10^{\text {th }}$ International conference. Moscow, November 14-16, 2013. Papers and proceedings. Symposium "Thesaurus Analysis of World Culture"] / ed. by Vl. A. Lukov. Moscow, Moscow University for the Humanities Publ. 80 p. Pp. 66-73. (In Russ.).

Grigorieva, I. A. and Yasinskaya, M. B. (2014) Topika romana Giuntera Graasa «Zhestianoi baraban» [The topics of Günter Grass' novel “The Tin Drum”]. Naucbnye trudy Moskovskogo gumanitarnogo universiteta, no. 10, pp. 23-30. (In Russ.).

Lukov, V. A. and Lukov, Vl. A. (2008) Tezaurusy: Sub'ektnaia organizatsiia gumanitarnogo znaniia [Thesauri: The subjective organization of humanities knowledge]. Moscow, The National Institute of Business Publ. 784 p. (In Russ.).

Lukov, V. A. and Lukov, Vl. A. (2013) Tezaurusy II : Tezaurusnyi podkbod k ponimaniiu cheloveka $i$ ego mira [Thesauri II: The thesaurus approach to the conceptualization of the person and his/her world]. Moscow, The National Institute of Business Publ. 640 p. (In Russ.).

Maslova, V. A. (2011) Vvedenie v kognitivnuiu lingvistiku [An introduction to cognitive linguistics]. 5 th edn. Moscow, Flinta Publ. ; Nauka Publ. 296 p. (In Russ.).

Sidorenko, E. V. (2010) Metody matematicheskoi obrabotki v psikbologii [Methods of mathematical procession in psychology]. St. Petersburg, Rech' Publ. 350 p. (In Russ.).

Faktornyi, diskriminantnyi $i$ klasternyi analiz [Factor, discriminant, and cluster analysis] (1989) / J.-O. Kim, C. W. Mueller, W. R. Klekka et al. : transl. from English ; ed. by I. S. Eniukov. Moscow, Finansy i statistika Publ. 215 p. (In Russ.).

Submission date: 13.05.2015.

Григорьева Ирина Андреевна - студент 5-го курса факультета культуры и искусства Московского гуманитарного университета. Адрес: 111395 , Россия, г. Москва, ул. Юности, д. 5. Тел.: +7 (499) 364-55-11. Эл. aspec: miriama@yandex.ru

Grigorieva Irina Andreevna, $5^{\text {th }}$ year Student, Faculty of Culture and Arts, Moscow University for the Humanities. Postal address: 5 Yunosti St., 111395 Moscow, Russian Federation. Tel.: +7 (499) 374-55-11.E-mail: miriama@yandex.ru 